\title{
Building an Effective Right-Hand Guitar Technique Around Injury Prevention Methods
}

\author{
Bráulio Bosi (University of Missouri, Kansas City, USA) \\ bosib@umkc.edu
}

\begin{abstract}
The right-hand technique of guitarists needs to move forward when it comes to injury prevention. Guitarists are often diagnosed with median neuritis, carpal tunnel syndrome, lateral epicondylitis, medial epicondylitis, intersection syndrome, digital flexor tenosynovitis, stenosing tenosynovitis, and De Quervain's syndrome as a result of faulty right-hand technique. The causes generally converge to the lack of warm-ups, compression of the forearm muscles, excessive wrist flexion, extension, or sideways deviations, and repetitive movements with simultaneous muscle tension or strained positions. Based on evidence, this article provides technical suggestions that reduces tension and theoretically decreases the chances of playing-related injuries.
\end{abstract}

Keywords: Guitar technique; right-hand injuries; musician's health; injury prevention.

Construindo uma Eficiente Técnica Guitarristica de Mão Direita Baseada em Métodos de Prevenção de Lesões

Resumo: A técnica de mão direita de violonistas precisa dar um passo a frente no quesito prevenção de lesões. Violonistas são comumente diagnosticados com neurite mediana, síndrome do túnel do carpo, epicondilite lateral, epicondilite mediana, síndrome de intersecção, tenossinovite de flexor digital, tenossinovite de estenose e síndrome de De Quervain como resultado de falhas na técnica de mão direita. Suas causas geralmente convergem para a falta de aquecimentos, compressão dos músculos do antebraço, excessiva flexão, extensão, ou desvios laterais do punho, e movimentos repetidos combinados com tensão muscular ou posições tensionadas. Baseado em evidências, este artigo propõe sugestões técnicas que reduzem tensão e teoricamente diminuem as chances de lesões causadas pela atividade musical.

Palavras-chave:Técnica violonística; lesões de mão direita; saúde do músico; prevenção de lesões.

Right-hand technique has been approached by guitar virtuosos and scholars in the search of accuracy and an ideal sound. While the evolution of right-hand technique from the methods of Fernando Sor, Dionisio Aguado, to the ideas of Abel Carlevaro, Aaron Shearer, Scott Tennant arguably achieved these goals, the health aspect has been largely ignored. Sung et al. (2013, p. 1563) points out that $45 \%$ of the injuries in guitarists are "strongly tied to the hand and wrist." Among such injuries, we could name median neuritis, carpal tunnel syndrome, lateral epicondylitis, medial epicondylitis, intersection syndrome, digital flexor tenosynovitis, stenosing tenosynovitis, and De Quervain's syndrome affecting their right-hand.

As some of these injuries could shorten or limit careers, and that treatment often includes ceasing the music activity for some time, guitarists should search for a right-hand technique that in addition to accuracy and tone quality, allows them to have a long, injury-free career. This article investigates the causes of the most common injuries caused by faulty right-hand technique and provides technical approaches that theoretically decreases the risk of playing related injuries.

\section{Identifying Causes}

Rosenbaum et al. call attention to musculotendinous overuse syndrome affecting the hands, wrists and forearms of musicians. The authors state that these injuries may be due to eccentric contraction "involving injury to the musculotendinous junction" as a consequence of "overstretching of contracting muscles," inflammation of the tenosynovium, or due to injury to "muscles, tendons, ligaments, and joint capsules, and tendon sheath inflammation” (ROSENBAUM et al., 2012, p. 1270). 
Starting by the right forearm, its improper use may also lead to a series of nerve entrapments such as median neuritis. To understand the impact that this type of injury has on guitarists, Rueda (2006, p. 76) explains that the median nerve participates in several motions utilized in guitar playing, as the nerve "takes electrical stimuli to a range of muscles whose job it is to flex the wrist and fingers, particularly the hand muscles that enable the thumb to pinch and oppose itself." This nerve travels through "a series of narrow gaps" in the forearm and in the carpal tunnel and may be directly affected by guitar playing activity. Rueda (2006, p. 76) states that for the forearms, "co-contraction leading to too much muscle tone at this level, repetitive gestures such as strumming or attacking steel strings with a plectrum, and any intense finger flexion-extension movements" without a proper warm-up routine "can damage this nerve." Other causes of damage in this nerve listed by the author are associated with the "prolonged compression of the front side of the forearm," such as "when the right forearm is rested against the lower bout of the guitar" (RUEDA, 2006, p. 76).

Another location where the median nerve is commonly trapped is in the carpal tunnel. Known as carpal tunnel syndrome, this entrapment is one of the most frequent complaints among guitarists. Rueda (2006, p. 76) explains that "all the tendons that flex the fingers and the median nerve must squeeze" through a narrow, tight and rigid gap on the "inner side of the wrist made up of the concave carpal bones." Because the space in the carpal tunnel is limited, repetitive friction can cause inflammation, compressing the median nerve (RUEDA, 2006, p. 76). Excessive wrist bending or flexion are known as significant risk factor for carpal tunnel syndrome in guitarists, and the symptoms include "tingling and numbness coupled with pain in the first three digits" (RUEDA, 2006, p. 76), as well as "muscle weakness" in the wrist's intrinsic muscles such as the flexor and opponens pollicis (GOODWIN, 2003)(See Figure 1). Without proper care, muscular atrophy may occur, limiting finger and thumb movements (RUEDA, 2006, p. 76).

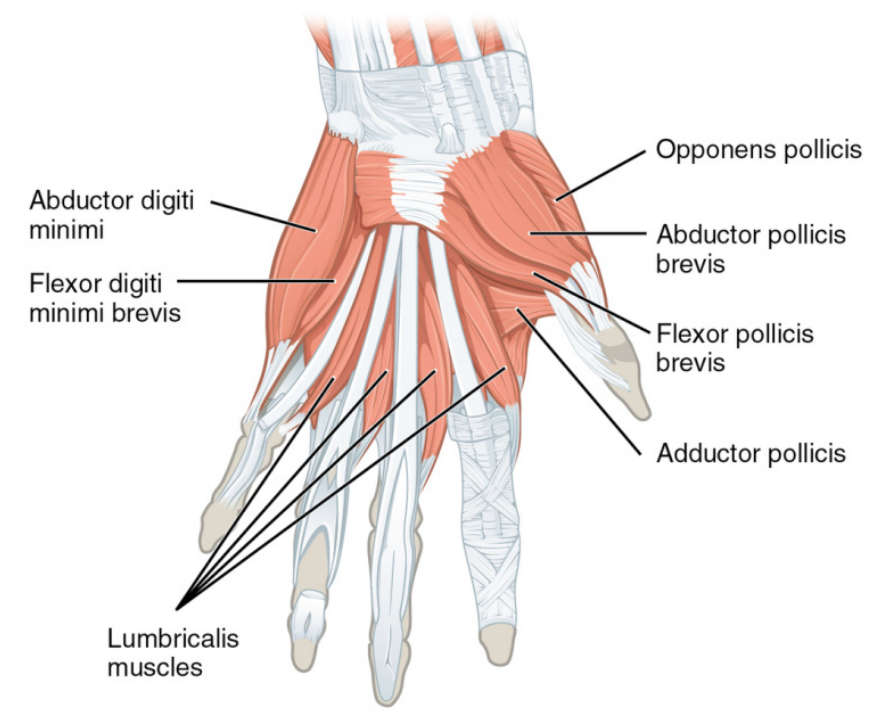

Figure 1. Muscles in the hand.

Source: Intrinsic muscles of the hand superficial.Wikimedia Commons, Available at <https://commons.wikimedia.org/wiki/ File:1121_Intrinsic_Muscles_of_the_Hand_Superficial_sin.png >. Accessed May 14, 2017.

Bending the right-wrist too much may trigger different injuries besides carpal tunnel syndrome, including lateral epicondylitis, also known as "tennis elbow," and medial epicondylitis, known as golfer's elbow. Although the names suggest that these injuries occur exclusively in athletes, they are also frequent in guitarists. Rueda $(2006,71-72)$ ex- 
plains that "forced wrist extension (or dorsal flexion) coupled with repetitive finger movements" are the causes of lateral epicondylitis, which is generally manifested as "localized pain on the outer side of the elbow or forearms," possibly "spreading towards the wrist, hand or shoulder." For medial epicondylitis, it occurs by "prolonged 'unsafe' wrist flexion," along with the "repetitive flexion-extension motion of the fingers against the resistance of the strings" (RUEDA, 2006, 71-72). Rueda (2006, p.72) explains that this type of tendonitis "affects the inner elbow at the point where it is attached to the flexor muscle of the fingers and the wrist flexors."

Rietveld (2013, p. 433) lists intersection syndrome, also known as "drummers' wrist," as another common wrist injury. According to the author, this is a "friction syndrome" with pain at the intersection of the extensor carpi radialis (longus and brevis) and extensor pollicis brevis muscles and abductor pollicis longus muscle in the forearm (See Figure 2); it is caused by a "combination of repetitive movements with simultaneous tension in both the wrist and thumb extensors" (RIETVELD, 2013, p. 433).

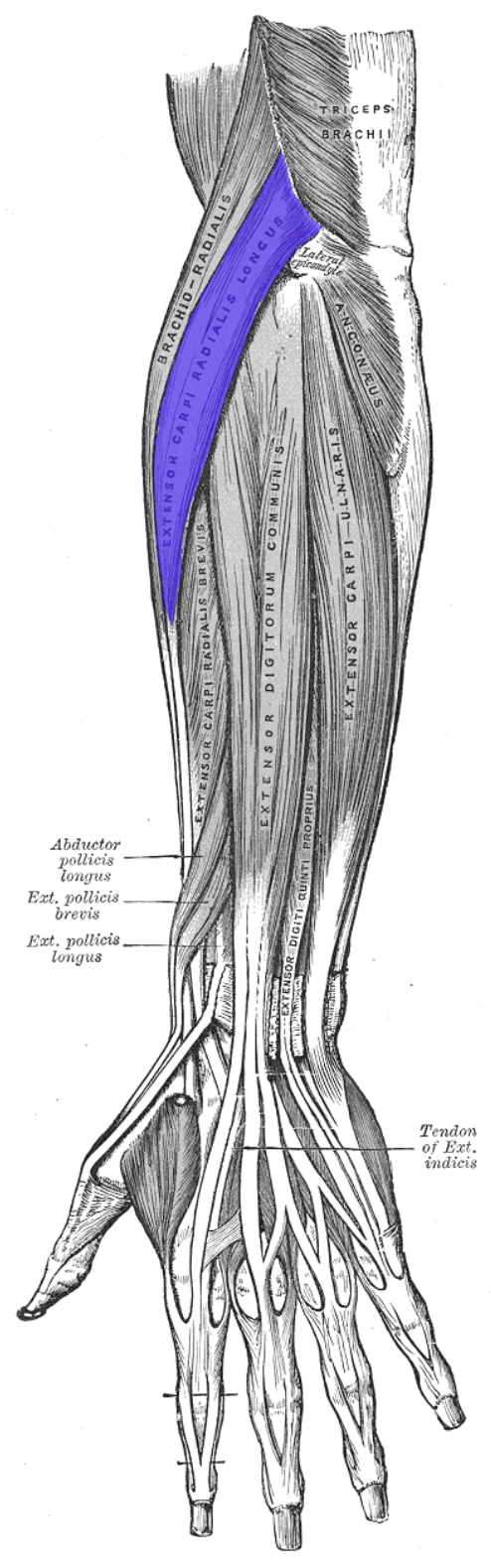

Figure 2. Wrist muscles. 
Of the common types of tenosynovitis in guitarists, Rueda highlights digital flexor tenosynovitis. To explain how this injury occurs, Rueda (2006, p. 73) describes how the "tendons of the flexor muscles in the fingers run through the carpal and metacarpal-phalangeal and interphalangeal joints" (See Figure 3) and that these joints are "covered by synovial sheaths that protect against the friction caused by movement of the tendon." According to the author, "excessive action and strained wrist positions may cause these sheaths [in the fingers] to swell or the synovial fluid to leak out and press against the tendon, particularly around the carpal” (RUEDA, 2006, p. 73).

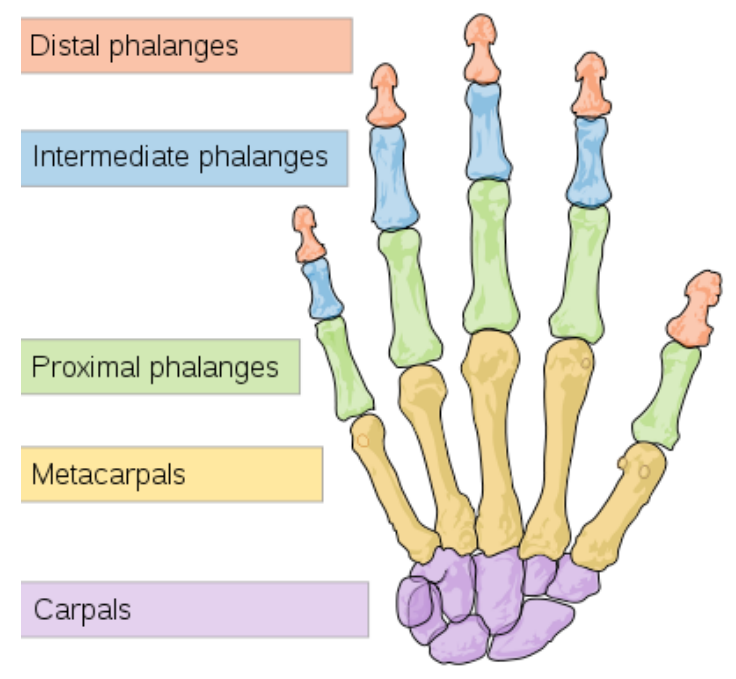

Figure 3. Bones of the hand.

Source: Main division on the (right) human hand. Wikimedia Commons, Available at <https://commons.wikimedia.org/wiki/ File:Scheme_human_hand_bones-en.svg >. Accessed May 14, 2017.

Guitarists are also vulnerable to the type of tenosynovitis known as trigger finger (stenosing tenosynovitis). Rueda (2006, p. 73) explains that when the tendon sheath swells and thickens, it pushes "against the tendon in the finger area," inflaming the tendon itself and forming a "palpable, painful nodule." The popular name of this injury reflects the symptoms of this injury. The nodule in the affected area creates resistance when the finger has to be opened (RUEDA, 2006, p. 73). This causes a "snapping sensation" that once repeated through multiple gestures may lock the finger as it is closed (RUEDA, 2006, p. 73). In guitarists, the middle and ring fingers are the most frequently affected (RUEDA, 2006, p. 73), and the causes of this injury are related to the "repeated movement or forceful use" of the fingers. ${ }^{1}$

Playing with ulnar deviation may lead to a type of tenosynovitis known as De Quervain's syndrome. Rueda (2006, p. 72) explains that "the long abductor tendons and short extensor thumb tendon slide through the same tunnel formed by the edge of the radius near the base of the thumb," and as they leave this tunnel, the tendons bend, "forming an angle that may exceed $90^{\circ}$ in certain thumb separation movements" (RUEDA, 2006, p. 72). Repeatedly making extension movements with the wrist held in ulnar deviation may trigger the syndrome by causing friction between the tendon, sheath and bone, leading to swelling and causing pain in the region (RUEDA, 2006, p. 72).

\section{Addressing the Causes}

The literature review of some of the most common injuries related to the right-hand 
guitar technique points to lack of warm-ups, compression of the forearm muscles, excessive wrist flexion, extension, or sideways deviations, and repetitive movements with simultaneous muscle tension or strained positions as the main causes of playing-related injuries in the right arm, hand and fingers.

Based on the causes of median neuritis at the forearm level, specific instruction for its prevention will depend on individual technique deficiencies. However, guitarists should generally pay attention to relaxation of both forearms. For an economical technique, they should apply only the minimal necessary tension and pressure to perform gestures that require the contraction of the forearm and release it as soon as the gesture is finished.

Regarding injuries that are caused by deviations of the right-hand, Bastepe-Gray (2014, p. 25) reminds us that the pulley mechanism in the forearms works more efficiently if the muscles and tendons are properly aligned, and that playing with ulnar or radial deviation of the right-hand wrist "may lead to excessive wear and tear in tendinous structures.” According to Rueda (2006, p. 56), ulnar deviation in the right-hand is "the forerunner to much tendonitis." The cause of these problems is that wrist deviation may narrow the canals though which the nerves pass to reach the hands. Guitarists with improper technique often flex or extend their wrists too far, compressing these tunnels even more (BASTEPE-GRAY, 2014, p. 25).

Besides guitarists, carpal carpal tunnel syndrome is also common in the general population and Goodwin gives directions for its prevention that guitarists may want to embrace. The author suggests that keeping the hands moving is beneficial as "frequent small variations in hand position reduce repetitive strain" (GOODWIN, 2016). When resting, intentionally keeping the hands with the palms up opens up the space between the ulna and radius (bones in the forearm) and "reduces compression on the palmar surface of the hand, wrist and forearm" (GOODWIN, 2016). Therefore, Goodwin (2016) advises that if one must work with hand palm-down, it should be placed in a palm-up or thumb-up position every moment possible. In contrast, if the hands are resting in a palm-down position, compression in the carpal tunnel and other vulnerable structures may occur, contributing to the injury (GOODWIN, 2016).

Goodwin (2016) suggests players minimize the amount of time spent closing together the thumb and little finger, which contracts or narrow the palm of the hand. According to Goodwin (2016), this movement contributes directly to carpal tunnel pressure. Guitarists should then reconsider their right-hand technique if it positions these fingers too close. They should also avoid having their hand in this position in other daily activities while away from the instrument. Goodwin agrees that if a job requires the use of the hands, leisure activities should not cause additional stress. As an example, the author states that instead of racquet sports, one should consider activities such as soccer (GOODWIN, 2016).

Goodwin (2016) also states that in order to avoid carpal tunnel syndrome individuals should try the majority of time to keep the wrists in a "near-neutral angle," neither flexed nor extended. The flexed and extended positions put significant "strain on the carpal tunnel," with the extended position causing nearly "three times as much strain" than the flexed position (GOODWIN, 2016). Though guitar playing sometimes requires a degree of both, the guitarist should look for a proper sitting position with the assistance of an adequate chair, ergonomic support and a suitably sized guitar that allows him to play with the right-wrist in near neutral position. When flexed or extended positions are unavoidable, 
guitarists should return as quickly as possible to a more neutral position.

Repetitive forceful movements are the aggravating factors for different injuries, including stenosing tenosynovitis. To target these issues, guitarists should distribute the required effort of finger gestures throughout the whole hand and arm instead of using only the muscles in the fingers to pluck a string. For example, when plucking a string the guitarist should use not only the movement of the multiple finger phalanges, but the weight of the hand and forearm as well to reduce tension in the fingers. Understanding how the fingers function in the hand may also be a powerful tool against injuries. Sung et al. (2013, p. 1657) states that the little finger motion is tied to the ring finger motion, that is, "when the little finger is lifted up, the ring finger is also lifted up." Considering that the ring finger is one of the main sites of the trigger finger, planning the movements of these fingers so that they are not doing opposing and conflicting gestures, such as extending the little finger while the ring finger is plucking a string will release any tension in the area creating a more natural movement.

\section{Neutral Position: A General Rule}

In general, guitarists should search for the already mentioned "neutral position" of the right-hand when playing. This means that the joints should remain around their mid-point of their entire range of motion (Mitchell, 2015). Mitchell (2015) states that the further from the midpoint the joint is moved, the more easily it will tire and the weaker it will be. According to Rueda (2006, p. 51), besides "ensuring joint stability, midline joint positions allow muscles to work at their repose length." "Because all movements are based on coordinated agonist-antagonist action,” Rueda (2006, p. 51) explains, "maintaining an extreme joint position may facilitate the action of some muscles but it seriously thwarts all antagonist movement."

Mitchell (2015) exemplifies the concept of neutral position saying that the fingers should stay "gently curved" as often as possible, even when they are not playing, as this is their midpoint, and that because "the tendons and muscles of the forearm extend down into the hands," the optimal position for the wrist is in straight alignment with the forearm "without unnecessary bends." Guitarists often neglect this optimal wrist position. Baste-Gray (2014, p. 25) points out that excessive flexion in the right wrist is a common issue, which over stretches the extensor tendons at the back of the hands and changes "the dimensions of the 'tunnel' at the wrist," increasing the chances of injury. Fjellman-Wiklund and Chesky (2006, p. 173-174), state that clinical practice shows hyper-flexed wrist positions are largely what generates musculoskeletal disorders in musicians, and "playing with a neutral wrist position generates fewer problems."

Marques et al.'s (2003, p. 13) study supports the above statements showing that flamenco guitarists play with the wrist in a more flexed position in comparison to classical guitarists, which is linked to their higher incidence of injuries. According to the authors, the sitting position of the flamenco guitarists with the guitar placed on the right leg causes them to over flex the right-wrist resulting in the thumb playing in an "almost exactly perpendicularly" position to the strings (MARQUES et al., 2003, p. 13). This position limits muscle freedom and increase tension in the region (MARQUES et al., 2003, p. 13). Their predominant playing technique, the apoyo (rest stroke), is also highlighted as one of the causes of excessive tension in the right hand. In the rest stroke technique, once a note is played, the finger remains pressed on the upper string, requiring "flexion and extension of 
the proximal phalanges of the three middle fingers" (MARQUES et al., 2003, p. 13). Though classical technique uses mostly "incomplete flexion of the middle phalanges of the same fingers" (MARQUES et al., 2003, p. 13), the flamenco technique is sometimes used by classical guitarists to emulate the flamenco sound or to play with more volume. Using this technique should be approached with caution to avoid tensing the hand for extended periods of time.

Rueda (2006, p. 15) describes the wrist as "a relatively vulnerable structure since it undergoes repetitive movement and traction and must stabilize finger movement whilst remaining flexible." Understanding the vulnerability of this part of the body, Hogg (2008, p. 37) advises guitarists to observe the tension in their wrists and stop to see whether they are bending their wrists "past a 45 degree angle." She argues that "poor technique is the most common culprit" in wrist injuries, and they are usually generated from "bending the wrist of the fretting hand excessively" (HOGG, 2008, p. 37).

Authors acknowledge though that slightly deviated positions can be beneficial occasionally. Mitchell (2015) states that when multiple notes are being played at the same time, the musician should look for a midpoint between the neutral positions for each finger activated, or even slightly change the wrist position so fingers do not have to perform awkward gestures. Muldowney (2010, p. 32) believes that fluid and flexible movements help prevent injuries based on the fact that one of the leading causes of repetitive strain injuries and overuse syndromes is "holding a rigid or static posture."

Muldowney (2010, p. 31) states that the optimal position for this hand is achieved with a "slightly bent-forward wrist position" with at least some degree of pronation. Rueda (2006, p. 52) goes further, advising guitarists to position their right wrists with no more than 15 to $20^{\circ}$ of radial or ulnar deviation, as this position allows the tendons to "glide through their sheaths with as little friction as possible." Concerned with muscle strains, compressive syndromes and other injuries, she also recommends that wrist flexion and extension should not exceed $15-20^{\circ}$. Keeping the wrists within this degree of flexion-extension "enhances muscle efficacy" and creates a "favorable angle of attack that facilitates the posterior action of the [finger] extensors as well as [optimal thumb] action" (RUEDA, 2006, p. 52).

\section{From the Whole Body to Individual Fingers}

When adjusting the right-hand to the neutral position, guitarists should observe if it is causing posture issues in other body parts. The footstool for example is known to cause a spinal deviation and often forces guitarists to raise the left-shoulder and drop the right-shoulder too much causing unnecessary tension (RUEDA, 2006, p. 47). An improper chair may make the guitar unstable requiring extra strength from the arms to keep it in place. It is important when looking for a neutral playing position to adjust the instrument to the guitarist's body, rather than the other way around. For guitarists, new ergonomic supports are available that allows them to place the guitar at any desirable height and inclined on any axis while keeping both feet on the floor, assisting a better overall posture.

The flexibility of the guitar placement allows us to cover a factor often left out by authors: the rotation of the guitar in the horizontal axis. If the guitar is inclined towards the guitarist's chest, it will be angled in a way that the musician will not have to arch the wrist as much to reach the strings (See Figure 4). If the guitar is positioned vertically, the guitarist either has to arch the wrist to reach the strings (See Figure 5) or move the shoulder forward to adjust the whole arm and hand positioning. 


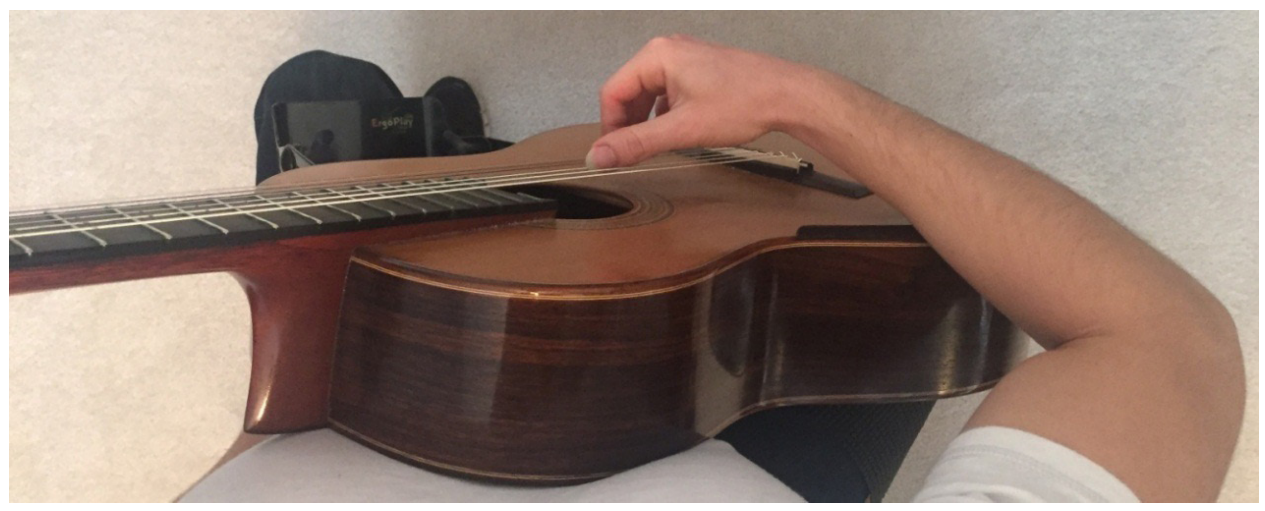

Figure 4 . Wrist gently curved to reach the strings.

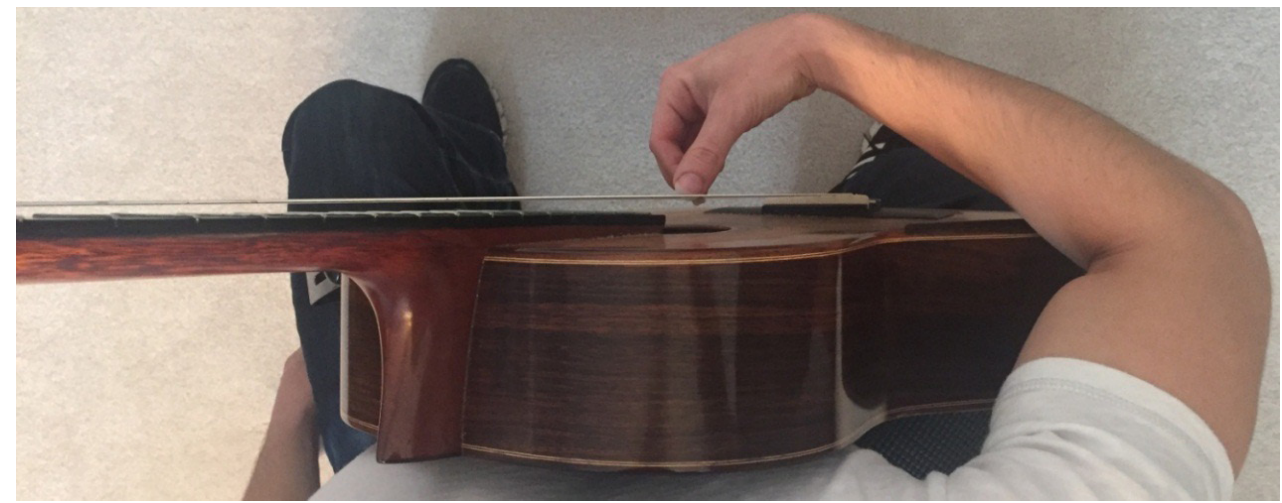

Figure 5. Wrist is arched to reach the strings.

Besides helping to keep the wrist flat, having the guitar leaning towards the chest creates more stability for the instrument without having to use the arm as a stabilizing force (See Figure 6). If the instrument is positioned vertically, it can bounce to either side, requiring the right arm to hold it in place (See Figure 7).

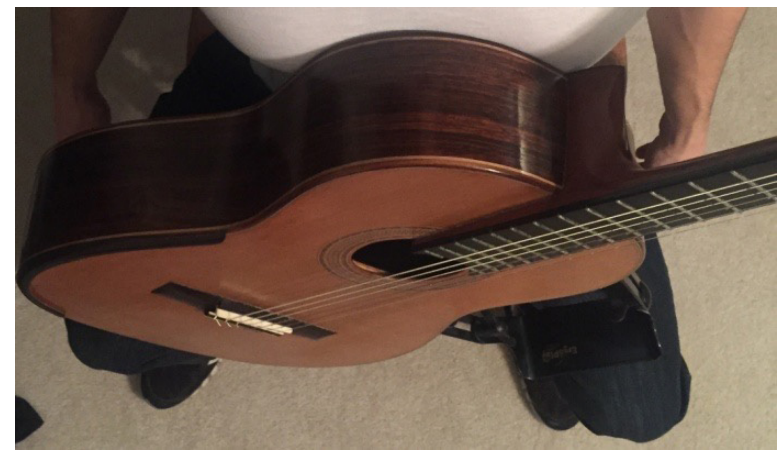

Figure 6. No extra forces required to hold the instrument.

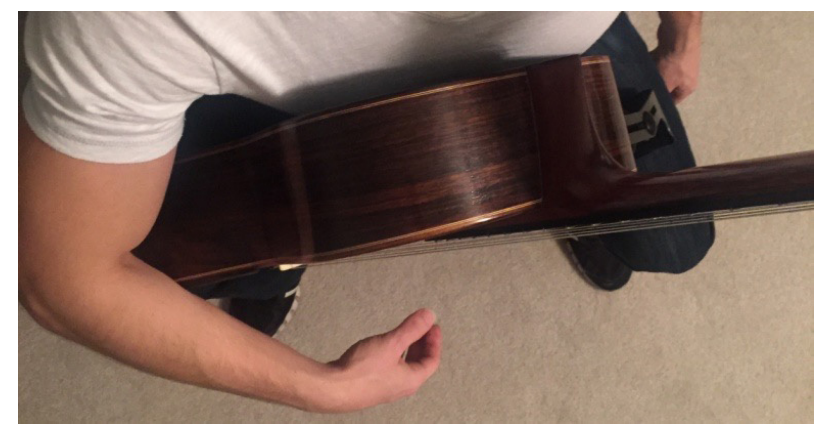

Figure 7. Right arm must be used to hold the instrument. 
The inclined position (Figure 8) makes the strings encounter the guitarist's hand, allowing the weight of the hand to rest on it, providing more relaxation and stability while adding an extra strength to "dig down" the strings towards the guitar's soundhole in the striking motion. In Figure 9, one can see that the guitar does not offer support to the hand. This requires entirely the muscles of the hand and arm to keep it stable while denying the use of the weight of the hand in the plucking gesture.

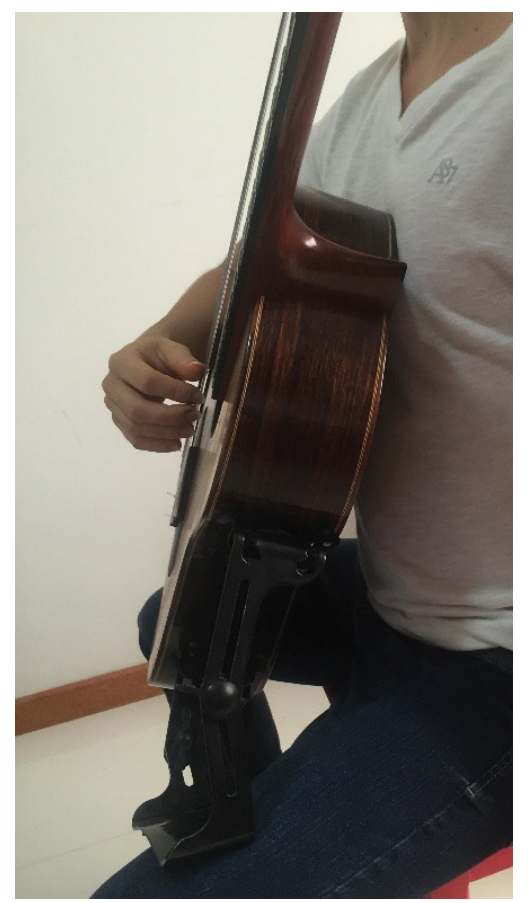

Figure 8. The inclined guitar supports the hand.

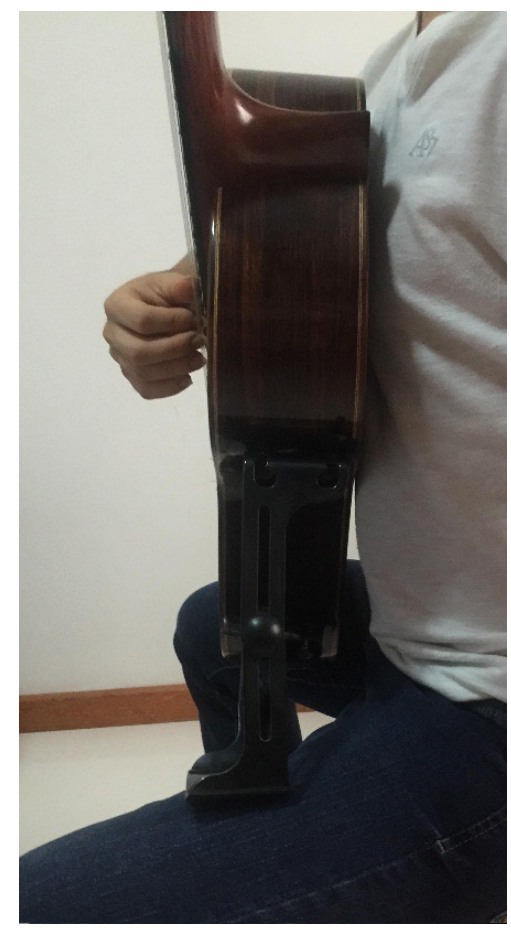

Figure 9. The guitar in a vertical position does not offer a support to the hand.

Using the weight of the right-hand to support finger gestures is not an unusual idea. These thoughts align with the ones of different authors that state guitarists should 
engage larger muscles to support the action of smaller ones. Bastepe-Gray (2014, p. 25) for example, says that the musician's trunk and shoulders need to support the forearms and hands so they can achieve their optimal functionality. Decreased engagement of the large muscles due to poor biomechanical habits, or due to lack of strength or flexibility, may cause the muscles in the arm and forearm to overcompensate with unnecessary tension (BASTEPE-GRAY, 2014, p. 25).

Forearm motion can also assist the right-hand fingers. Mitchell (2015) points out that their rotation can "add power" to many playing gestures and make it possible for the fingers "to fall where they are needed." Mitchell (2015) emphasizes that the forearm muscles must remain relaxed when forearm rotation is used to "relieve the fingers from awkward positions and unnecessary muscular motion," but that forearm rotation should be only used sporadically. When "the forearm muscles are tensed in a rotated position, the space between the two bones can become restricted and cause friction in the tendons and connective tissues" (MITCHELL, 2015). Muldowney (quoted by BASTEPE-GRAY, 2014, p. 25) explains that our forearm muscles "are optimally relaxed when our palms are facing each other," and that "the farther away they are from this position, the more isometric contraction" is needed in the muscles responsible for either supination or pronation of the hands.

After engaging larger muscles to support their right-hand, guitarists need to understand the mechanics of their fingers in order to use them more efficiently. Mitchell (2015) explains that "the thumb has the flexibility to move in a circular motion," while the other fingers primarily only move up and down. With these mechanics in mind, she points out that if the musician restricts the thumb movements to "forwards and backwards," not allowing it to "circulate freely from its base joint, it can become stiff, unreliable, and susceptible to strain” (Mitchell, 2015). This suggests that the guitarist, whenever possible, should strike the string with a semi-circular motion allowing the thumb to complete its circular trajectory to return to its resting position.

Muldowney (2010, p. 31-32) discusses the overall posture of the fingers stating that they should be "relaxed, with the fingers together" and stretching only as needed. To achieve this posture the author suggests that the guitarist should take care to not have the right hand in a high degree of supination (rotated towards a palm up position), or to not leave the fingers that are not being used stretched out (MULDOWNEY, 2010, p. 31-32). Mitchell (2015) adds that "fingers should operate independently so that the muscular effort of the finger being used does not result in muscular activity" of the other fingers. The ring finger is, however, an exception. The ring and little fingers are connected, and trying to make them operate independently may lead to injury (MITCHELL, 2015).

\section{From the Music Score to the Fingers}

Rueda expresses concern with increased tension on the right-hand during fast passages, especially on how they affect the extensor muscles of the wrists and fingers. According to her, these muscles "are frequently affected by intense action involving force and speed” (RUEDA, 2006, p. 70). Rueda (2006, p. 70) states that even though these muscles possess fast contractile fibers, they are easily tired: forcing them "to maintain wrist stability while repeatedly performing rapid movements, runs the risk of overloading the musculature." While Rueda's concern is true, guitarists can explore known alternative right-hand fingerings to avoid overloading the fingers. Fingerings are important to guitarists because they affect voice-leading and timbre; however, it may sometimes be advised to sacrifice some level of musicality for the sake of a less stressful hand position. 
Strategies for reducing right-hand tension include playing scales incorporating the thumb or ring finger rather than only alternating the index and middle fingers, and playing arpeggios using the thumb to eliminate or reduce the use of the ring finger. The example below shows different approaches to right-hand fingerings on a scale:

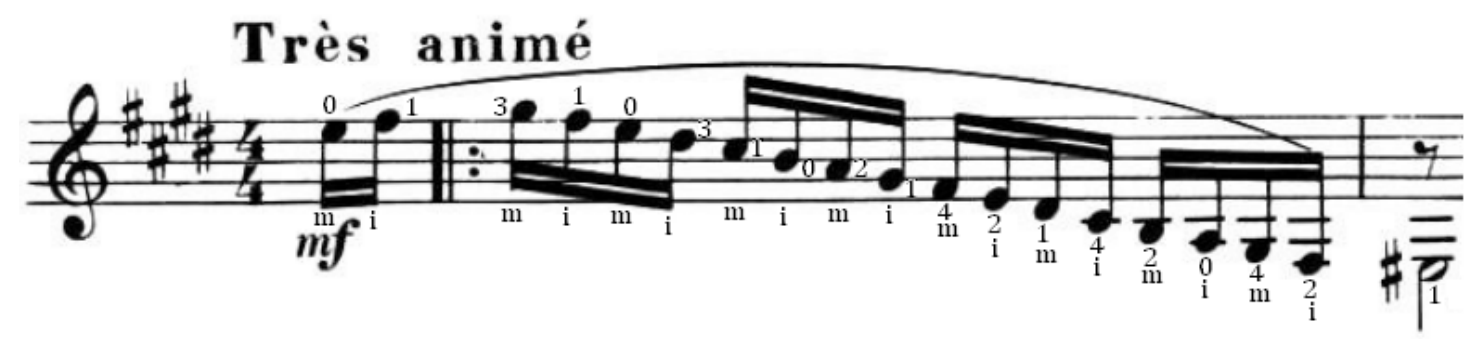

Figure 10. Fragment of Heitor Villa-Lobos' Etude $\mathrm{n}^{\circ} 7$ with a conventional right-hand fingering. Source: VILLA-LOBOS, Heitor (1953). Etude no. 7. In: Douze Études Pour Guitare. Paris: Éditions Max Eschig. p.18.

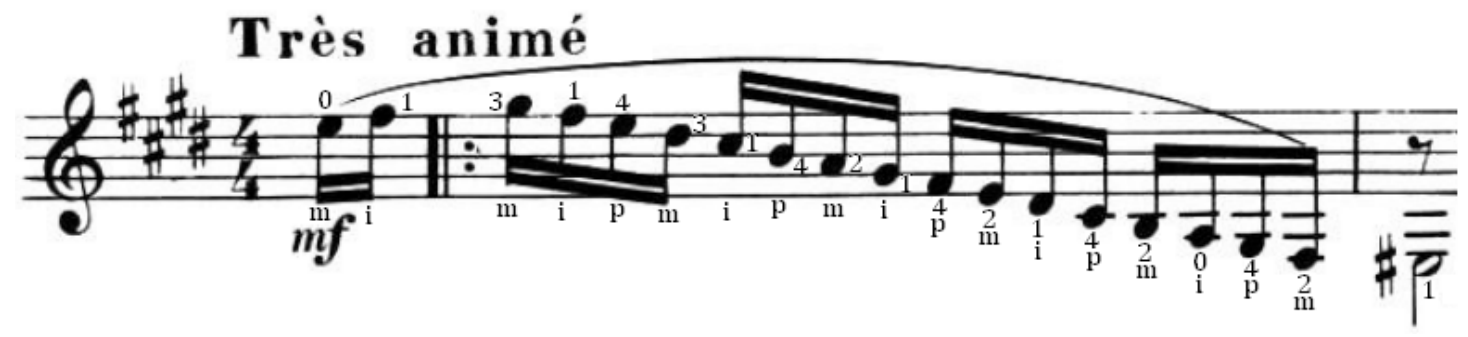

Figure 11. Fragment of Heitor Villa-Lobos' Etude $\mathrm{n}^{\circ} 7$ with an alternative right-hand fingering.

Source: VILLA-LOBOS, Heitor (1953). Etude no. 7. In: Douze Études Pour Guitare. Paris: Éditions Max Eschig. p.18.

Villa-Lobos' Etude $n^{\circ} 7$ is a guitar piece known for its virtuosity. In Figure 10 the guitarist only alternates the right-hand fingers "m" and "i," which may cause fatigue as the speed required often leaves little to no time to relax the fingers before they are re-activated. Figure 11 shows an approach using three fingers: "p," “m,” and "i.” With this approach, each finger has extra time to release tension before being utilized again.

Guitarists may also incorporate the thumb in arpeggios (See Figures 12 and 13):

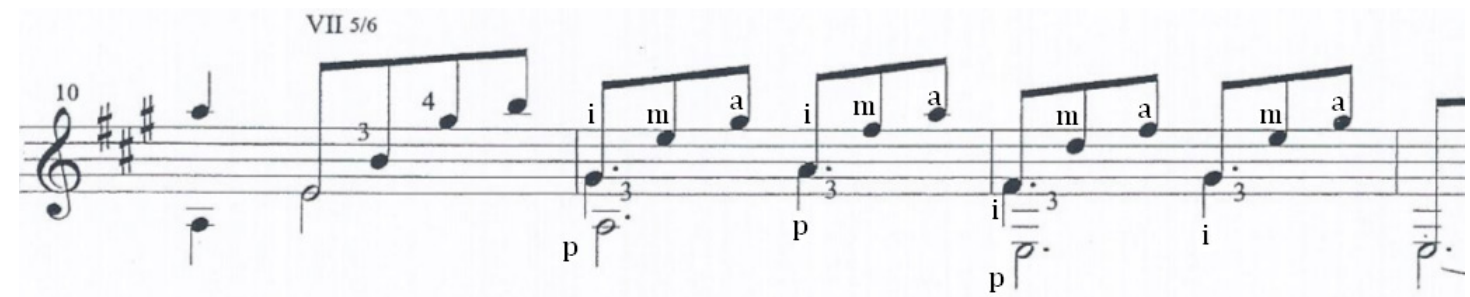

Figure 12. Fragment of Antonio Lauro's Pasaje Aragüeño with a conventional right-hand fingering.

Source:LAURO, Antonio (2005). Pasaje Aragüeño. In: Antonio Lauro Works for Guitar, Volume 5. Caroni Music. p. 11.

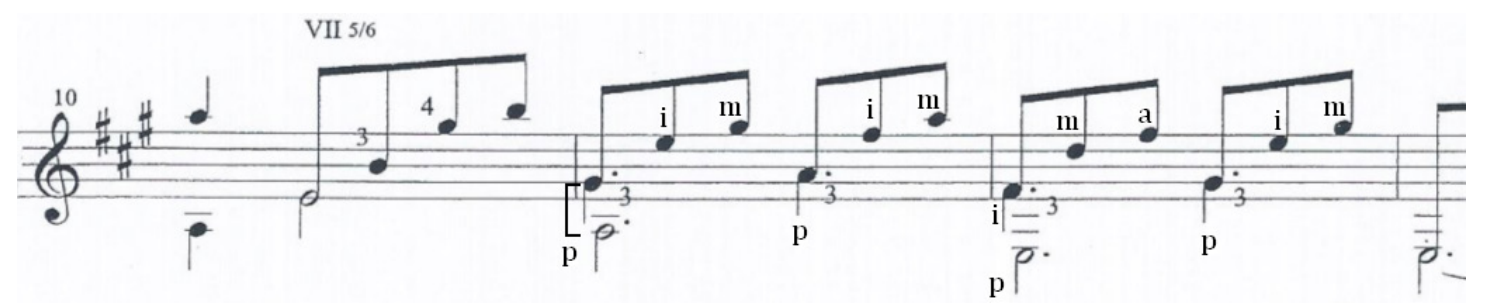

Figure 13. Fragment of Antonio Lauro's Pasaje Aragüeño with an alternative right-hand fingering.

Source: LAURO, Antonio (2005). Pasaje Aragüeño. In: Antonio Lauro Works for Guitar, Volume 5. Caroni Music. p. 11. 
The repeated use of the "a" finger in fast passages showed in Figure 12 may generate tension in the right-hand, especially when it has to stretch in order to reach the "e" string. If this is the case, guitarists can eliminate the recurrent use of the "a" finger by using fingers "p," "m," and "i," instead and re-striking the thumb in a continuous motion through two neighbor strings when possible (See Figure 13).

While the use of the alternative finger patterns in Figures 11 and 13 may alter the timbre of the passages or require extra dexterity to maintain an uniform sound, the excerpts show that using carefully planned alternative fingerings can be an effective way to save energy and reduce tension, particularly in fast passages.

\section{Conclusion}

This article investigated the main playing-related injuries caused by right-hand guitar technique and concluded that most of these injuries occur because of the lack of warm-ups, compression of the forearm muscles, excessive wrist flexion, extension, or sideways deviations, and repetitive movements with simultaneous muscle tension or strained positions as the main causes of playing-related injuries in the right arm, hand and fingers.

An efficient way of addressing the causes of these playing-related injuries is to adopt a neutral or near-neutral position to the right-arm, hand and fingers, while avoiding other body parts becoming strained because of this positioning. Adapting the instrument to the guitarist is therefore more effective than adjusting the player to the instrument as different ergonomic supports are available to assist placing the guitar at any height and degrees of inclinations in any axis.

Guitarists should also engage larger muscles to assist finger gestures to ensure that the fingers make just the minimum effort to pluck the strings. Inclining the guitar towards the guitarist provides more stability to the instrument and deny any need of stability assistance from the hands while also allowing the musician to utilize the weight of his hand to push down the string in the playing gesture.

Fingering choices play an important role to avoid hand fatigue. In fast right-hand passages guitarists may choose to utilize alternative fingerings for the sake of relaxation and fluidity in the gesture. Instead of the common alternation of two fingers in scale, guitarists can add the thumb making it a three-finger alternation to allow more resting time to each finger before its re-activation. In fast successive arpeggios, when the "a" finger causes tension to the gesture, its use can be avoided or replaced by the thumb as the example provided in this article showed.

The suggestion provided here addresses the main causes of playing-related injuries triggered by the guitar right-hand technique and theoretically decreases the risk of such injuries. By no means are they the only and definitive solutions to injury prevention in guitarists and as new issues appear, guitarists will have to adapt to approach them. New research in the field of performing arts medicine will help us make informed decisions as guitar technique continues to evolve.

\section{Endnotes}

1. Trigger finger causes and treatment.WebMD, Available at < http://www.webmd.com/osteoarthritis/guide/trigger-finger>. Accessed April 2, 2017. 


\section{References}

BASTEPE-GRAY, Serap. Healthy hands: A Primer in Injury Management for guitarists. Soundboard, v. 40, n. 2, p. 24-32, 2014.

FJELLMAN-WIKLUND, Anncristine;CHESKY, Kris. Musculoskeletal and general health problems of acoustic guitar, electric guitar, electric bass, and banjo players. Medical Problems of Performing Artists, v. 21, n. 4, p. 169-177, 2006.

GOODWIN, Siana. (2003). Carpal tunnel syndrome and repetitive stress injuries. Ways to avoid it and work with it: A Rolfer's perspective. Massage $\&$ Bodywork magazine, Available at <http:// www.massageandbodywork.com/>. Accessed April 2, 2017.

HOGG, Karen. Here's how: Play without pain. Acoustic Guitar, v. 18, n. 11, p. 34-37, 2008.

MARQUES, Djalma N.; ROSSET-LLOBET, Jaume; MARQUES, M. F. F.; GURGEL, I.G.D.; AUGUSTO, L.G.S.Flamenco guitar as a risk factor for overuse syndrome. Medical Problems of Performing Artists, v. 18, n. 1, p. 11-14, 2003.

MITCHELL, Tamara. (2015). A painful melody: Repetitive strain injury among musicians. Working Well Ergonomics Information Website, Available at <http://www.working-well.org/articles/pdf/Musicians2.pdf>. Accessed April 2, 2017.

MULDOWNEY, Micah. Optimal muscle and tendon extension for guitar players.” Soundboard, v. 36, n. 4, p. 30-33, 2010.

RIETVELD, A. B. M.Dancers' and musicians' injuries. Clinical Rheumatology, v. 32, p. 425-434, 2013.

ROSENBAUM, Andrew J.; VANDERZANDEN,Jacqueline; MORSE, A. S.; UHL, R. L. Injuries complicating musical practice and performance: The hand surgeon's approach to the musician-patient. The Journal of Hand Surgery, v. 37, n. 6, p. 1269-1272, 2012.

RUEDA, Virginia A. (2006). The healthy guitarist: How to save energy, avoid injury and get more out of your playing. Madrid, Spain:Acordes Concert.

SUNG, Kiseok; CHANG, Joonho;FREIVALDS, Andris; KONG, Yong-Ku. Development of the two-dimensional biomechanical hand model for a guitar player. Proceedings of the Human Factors and Ergonomics Society Annual Meeting, v. 57, n. 1, p. 1653-1657, 2013.

Bráulio Bosi is a music teacher and an awarded guitarist. He graduated in music education from the Federal University of Espírito Santo (Brazil) and possesses a master's degree from Oklahoma City University and a doctoral degree from the University of Missouri-Kansas City, both in classical guitar performance. Dr. Bosi researches in the field of performing arts medicine and has co-authored a book on musician's health entitled "A Saúde do Músico em Foco: Olhares Diversos." 